\title{
An Optimal Gear Shifting Strategy for Heavy Trucks with Trade-off Study between Trip Time and Fuel Economy
}

\author{
X.X. Zhao ${ }^{1 *}$, A. H. Ing ${ }^{2}$, N. L. Azad ${ }^{2}$ and J. \\ McPhee ${ }^{2}$
}

${ }^{1}$ University of Science and Technology Beijing School of Mechanical Engineering, XueYuan Street 30, Beijing 100083, China

${ }^{2}$ University of Waterloo- Department of Systems Design Engineering, 200 University Avenue West, Waterloo N2L3G1, Canada

E-mail: zhaoxinxin718@ hotmail.com

E-mail: adam.ingwu@ gmail.com

E-mail: nlashgarianazad@uwaterloo.ca

E-mail: mcphee@uwaterloo.ca

*Corresponding author

\begin{abstract}
Advances in vehicle technology have improved driving performance and fuel efficiency. Further increases in fuel efficiency of a heavy mining truck can be achieved by optimizing gear shifting strategy. Using characteristic tests of the diesel engine, a high-fidelity model of a mining truck was built in MapleSim and a consistent low-order model was developed in Matlab. The dynamic programming approach has been applied to the low-order model of the specialized off-road 30-tonne mining truck over a fixed route in a mining area. There were two competing objectives: fuel use and trip time. Weighting coefficients were used to combine these objective functions to a single value, and a Pareto curve was created to analyse the effect of the weights on the fuel use and trip time. Using the control strategy obtained from dynamic programming on the high-fidelity model, it is estimated that forty-thousand litres of fuel can be saved annually based on a mine which produces 110 kilotons of coal per day.
\end{abstract}


An Optimal Gear Shifting Strategy for Heavy Mining Trucks with Trade-off Study between Trip Time and Fuel Economy

Keywords: dynamic programming; heavy mining truck; gear shifting strategy; Pareto curve.

Biographical notes: Xinxin Zhao is a $\mathrm{PhD}$ student in the school of mechanical engineering at the University of science and technology Beijing, China. Her research interests are in the field of motion dynamics and gear shifting control.

Adam $\mathrm{Hu}$ Ing has graduated from the department of systems design engineering at University of Waterloo. His research involves the parallel hybrid electric vehicle research project.

Nasser Lashgarian Azad is an Assistant Professor in Systems Design Engineering at University of Waterloo. His primary research interests lie in modelling, estimation and control of complex dynamic mechanical and multi-domain physical systems, with special emphasis on advanced modelling and model reduction methods, sensitivity analysis techniques, nonlinear and optimal control, with applications to advanced vehicle systems, such as modern automotive powertrains and vehicle dynamics control systems.

John McPhee is a Professor in Systems Design Engineering at the University of Waterloo, Canada, and the Canada Research Chair in System Dynamics. His main area of research is multibody system dynamics, with principal application to the analysis and design of vehicles, mechatronic devices, biomechanical systems, and sports equipment. He was the Executive Director of the Waterloo Centre for Automotive Research until 2009, after which he spent a sabbatical year at the Toyota Technical Centre in Ann Arbor, Michigan. He is a Fellow of the American Society of Mechanical Engineers and the Canadian Academy of Engineering.

\section{Introduction}

Heavy trucks are used in mining operations to move dirt and ore. These payloads often weigh up to 100 tons. The trucks operate for over 8 hours daily, and thus consume significant amounts of fuel during their operating lifetime. Since oil is a non-renewable resource and becoming more expensive, operational costs can be reduced by improving driving 
An Optimal Gear Shifting Strategy for Heavy Mining Trucks with Trade-off Study between Trip Time and Fuel Economy

efficiency. One method to reduce fuel consumption is to replace the diesel powertrain with a hybrid electric powertrain; however, it is very expensive to replace an entire fleet of mining trucks. A more cost-coefficient approach to save fuel over a known route is to optimise the vehicle gear shifting strategy.

The optimal gear shifting strategy will reduce the fuel consumption by selecting the most efficient gear. It can be obtained using a mathematical model of the powertrain and an optimization algorithm that will find the optimal control law.

Two types of models are used in this work: high fidelity and low-order models. High-fidelity models capture most of the dynamics of the system but solve slowly. One popular powertrain model is the Mean Value Powertrain model, which contains the Mean Value Engine Model (MVEM) (Saerens et al, 2009). Low-order models solve quickly, but may lose many details in the system. Often, low-order models are used to derive a control strategy instead of a high-fidelity model because of the computational efficiency ( $\mathrm{Fu}$ and Bortolin, 2012).

Low-order models are often called control-oriented model because they are built for control design approaches, such as Pontryagin's minimum principle (Chang and Morlok, 2005) and dynamic programming (Mensing et al., 2013; Hellström et al, 2006; Liamas et al, 2013).

Dynamic programming requires a control-oriented model of the vehicle, and all trip information. In the past, dynamic programming has been formulated to minimize fuel consumption for passenger cars ( $F$. Xavier L.C., 2012), city buses (Nouveliere et al., 2008) and heavy trucks (Fu and Bortolin, 2012, Fröberg et al., 2006; Hellström et al, 2009; Hellström et al, 2010). Dynamic programming has also been formulated to minimize both trip time and fuel consumption. It is utilized to carry out a fuel-optima gear shift map and a throttle control problem over many different acceleration profiles (Kim et al., 2007). The optimal gear shift strategy for passenger vehicles equipped with an AMT has been designed by using dynamic programming (Ngo et al., 2013). Simulation results over the standard driving cycles represent a substantial improvement in the fuel economy. Since there are not standard driving cycles for the heavy duty truck, the optimal gear shift strategy is extracted based on the look-ahead road conditions. Besides, the look-ahead information can be used for improving fuel efficiency. There is a device exhibiting the gear shifting strategy respect to driving condition data such as vehicle mass, driving resistance and topography data(Sauter et al, 2009).

A control-oriented model and a high-fidelity model of the vehicle powertrain, which are consistent with each other, are developed. The 
An Optimal Gear Shifting Strategy for Heavy Mining Trucks with Trade-off Study between Trip Time and Fuel Economy

high-fidelity model includes: a diesel engine, automatic transmission, drive shaft, final drive and wheels. The fuel consumption model is based on experimental data for the engine in the baseline vehicle, which is a 30-tonne mining truck. The road topography for a route in North-Western China is collected beforehand, and the gear shifting and vehicle velocity are optimized for this trip. By tuning the weighting coefficients associated with fuel consumption and time in the objective function, driving behaviour can be obtained which balances travel time and fuel consumption. Using a high-fidelity model, it's shown that the gear shifting strategy improves both the fuel consumption and travel time.

The next section describes the low and high-fidelity models of vehicle and the comparison between two models with given gear shifting strategy. In the third section, the optimal control law for a known route is obtained from the dynamic programming approach. The fourth section shows the result of a trade-off study applied to the high-fidelity model, and the model in the loop simulation is shown.

\section{Modelling}

Two models are presented in this section: a high-fidelity model and a low-order model. First the similarities in both models are described then the differences are highlighted.

A mining truck powertrain usually consists of a diesel engine, automatic transmission, and final (output) drive. The final drive is assumed to be a fixed gear ratio with no power losses. The vehicle wheels are assumed to have no slip. Figure 1 depicts the inputs and outputs of each subsystem of the driveline in a mining truck, where $M_{x}$ is the torque and $\Phi_{\mathrm{x}}$ represents the angle.

Figure 1 Schematic of a mining truck powertrain

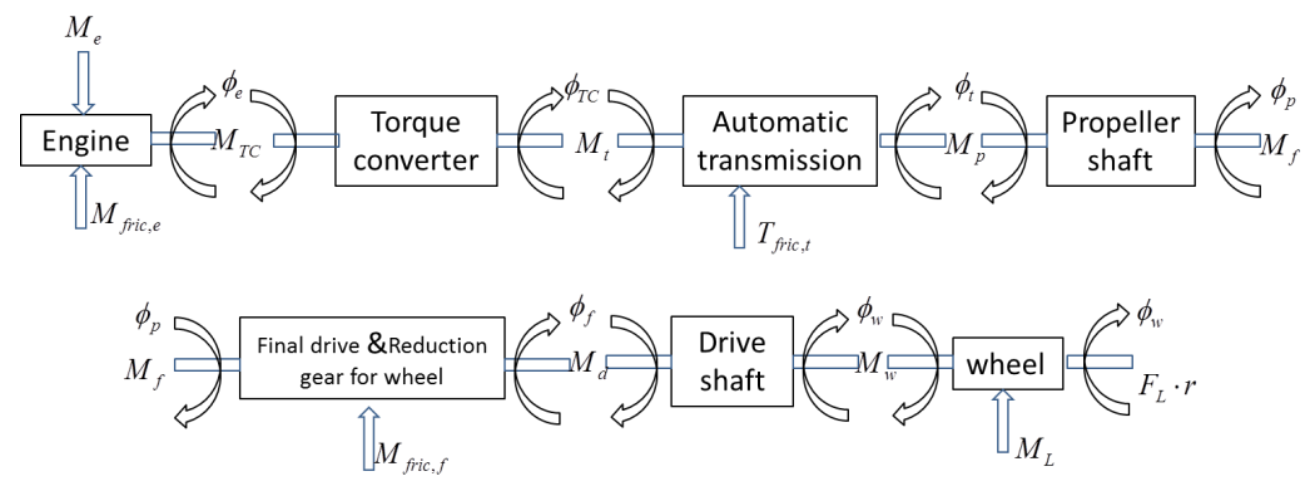


An Optimal Gear Shifting Strategy for Heavy Mining Trucks with Trade-off Study between Trip Time and Fuel Economy

\subsection{Vehicle longitudinal dynamics}

Both the high-fidelity and low-order model assume only the longitudinal dynamics of the truck is important. The equations for longitudinal dynamics can be found in the following equations (Guzzella and Sciarretta, 2007, Ivarsson et al., 2009). The frictional force $F_{L}$ is the sum of air drag, rolling resistance, and gravitational force down the sloped road. The torque due to friction force and torque balance formula of wheel is shown in Eq. 1 and 2 and the slope of the road is represented by $\theta$. The other parameters can be found in Table 1 .

$$
\begin{aligned}
& F_{L} \cdot r=\frac{1}{2} C_{a i r} A_{l} \rho_{a} r^{3} \dot{\phi}_{w}^{2}+r m g c_{r 1} \cos (\theta)+r m g \sin (\theta) \\
& J_{w} \ddot{\phi}_{w}=M_{w}-F_{L} \cdot r-M_{L}
\end{aligned}
$$

Table 1 Model parameters

\begin{tabular}{cccccccc}
\hline Parameter & Symbol & Value & Unit & Parameter & Symbol & Value & Unit \\
Vehicle mass & $\mathrm{m}$ & 24500 & {$[\mathrm{~kg}]$} & Final drive & $\mathrm{i}_{\mathrm{f}}$ & 12.5 & \\
Wheel radius & $\mathrm{r}$ & 0.734 & {$[\mathrm{~m}]$} & Air density & $\rho$ & 1.21 & {$\left[\mathrm{~kg} / \mathrm{m}^{3}\right]$} \\
Frontal area & $\mathrm{A}_{\mathrm{f}}$ & 7 & {$\left[\mathrm{~m}^{2}\right]$} & Gear 1 ratio & $\mathrm{i}_{1}$ & 5.182 & \\
Air drag & $\mathrm{C}_{\mathrm{air}}$ & 0.7 & & Gear 2 ratio & $\mathrm{i}_{2}$ & 3.188 & \\
Rolling & $\mathrm{c}_{\mathrm{r} 1}$ & 0.03 & & Gear 3 ratio & $\mathrm{i}_{3}$ & 2.021 & \\
Wheel inertia & $\mathrm{J}_{\mathrm{w}}$ & 5 & {$\left[\mathrm{~kg} \cdot \mathrm{m}^{2}\right]$} & Gear 4 ratio & $\mathrm{i}_{4}$ & 1.383 & \\
Engine & $\mathrm{J}_{\mathrm{e}}$ & 1.54 & {$\left[\mathrm{~kg} \cdot \mathrm{m}^{2}\right]$} & Gear5 ratio & $\mathrm{i}_{5}$ & 1 & \\
Cylinders & $\mathrm{n}_{\mathrm{cyl}}$ & 4 & & & & &
\end{tabular}

\subsection{High Fidelity Powertrain Model}

This is based on the equations given in (Chan et al., 2007), and the high-fidelity model is a forward quasi-static model regarding the throttle angle as input and mass of fuel as output. MapleSim with the Driveline library is used to model the mining truck powertrain. Parameters used in the mean value engine model with turbocharger are shown in Table 1 and the Nomenclature. Mining trucks have 4 planetary gears which can produce 5 discrete ratios by (dis)engaging clutches. The MapleSim model of an automatic transmission is introduced here. 
An Optimal Gear Shifting Strategy for Heavy Mining Trucks with Trade-off Study between Trip Time and Fuel Economy

\subsubsection{Mean value engine model}

The engine is modeled using the Mean Value Engine Model (MVEM), which is a complex model that captures physical dynamics such as fuel mass flow rate, pressure, and temperature. Diesel engines often use turbochargers for extra power. Shown in Figure 2, The MVEM breaks down the engine model into sub-models: compressor, turbine, intake manifold, exhaust manifold, and combustion and torque production.

Figure 2 A schematic diagram of a turbocharged diesel engine

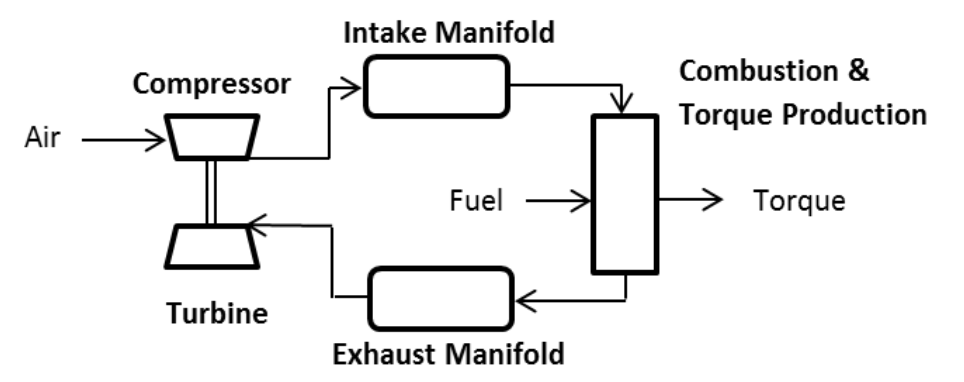

The turbine and compressor are mechanically connected; when air from the exhaust moves past the turbine, it causes the turbine to spin, subsequently spinning the compressor. The compressor compresses the entering air which flows into the intake manifold. As shown in equation 3, the first law of thermodynamics is used to relate the compressor torque $M_{c}$ to the mass flow through the compressor. The reader is referred to the Nomenclature section at the end of the paper for definitions of the other variables and parameters.

$$
M_{c}=\frac{\dot{m}_{c} C_{p a} T_{a m b}}{\eta_{c} \omega_{t c}}\left[\left(\frac{p_{c x}}{p_{a m b}}\right)^{\frac{\gamma-1}{\gamma}}-1\right]
$$

The intake manifold ensures the engine cylinders get sufficient air for combustion. The mass flow rate for the intake manifold is described by the ideal gas law Eq. 4.

$$
\dot{m}_{i m}=\dot{m}_{c}-\dot{m}_{i e}=\frac{V_{i m}}{R T_{i m}} \cdot \frac{d p_{i m}}{d t}
$$

A turbocharged diesel engine operates differently than a naturally aspirated gasoline engine. At the end of the compression stroke, the diesel engine injects fuel into the engine cylinder just before the desired 
An Optimal Gear Shifting Strategy for Heavy Mining Trucks with Trade-off Study between Trip Time and Fuel Economy

start of combustion. The expansion of gases (hot air and emissions) from the combustion process pushes against the cylinder to create mechanical power. Seen in Eq. 5, the mass flow rate is dependent on the mass of fuel per cylinder and per stroke $\left(\mathrm{u}_{\mathrm{f}}\right)$ and number of engine strokes.

$$
\dot{m}_{f}=\frac{u_{f} \dot{\phi}_{e} n_{c y l}}{n_{r}}
$$

Derived from the definition of indicated thermal efficiency, the indicated power $P_{\text {ind }}$ is :

$$
P_{\text {ind }}=\dot{m}_{f} Q_{l h v} \eta_{\text {ind }}
$$

The engine rotational dynamics model is a simple torque balance:

$$
M_{\text {ind }}-M_{f}-M_{\text {load }}=J_{e} \omega_{e}
$$

The difference between the turbine exhaust gas pressure and the atmosphere is not ignored. The drop in gas pressure from crossing the exhaust manifold is shown in Eq. 8 (Yanakiev and Kanellakopoulos, 1995).

$$
p_{e x}=\frac{1}{2}\left\{p_{i m}+\sqrt{p_{i m}^{2}-4 m_{e x}^{2} k_{0}\left(T_{i m}+T_{e x}\right)}\right\}
$$

The rotational dynamics of the turbine-compressor shaft are described by Euler's equation, where the moment of inertia of turbocharger rotor is denoted by $J_{t c}$ :

$$
M_{t}-M_{c}=J_{t c} \dot{\omega}_{t c}
$$

These equations for the MVEM with turbocharger are used in the high-fidelity model and implemented in MapleSim.

\subsubsection{Gearbox}

The automatic gearbox in a mining truck consists of multiple planetary gears connected together. This has the advantage of a large gear ratio, reduced weight, and high torque output. In total, there are 4 planetary gearsets and 6 clutches. The structure of the gearbox can be found in Figure 3, where $\mathrm{P}, \mathrm{B}$ and $\mathrm{C}$ represent the planetary set, brake and clutch respectively.

Figure 3 Gearbox model in MapleSim 


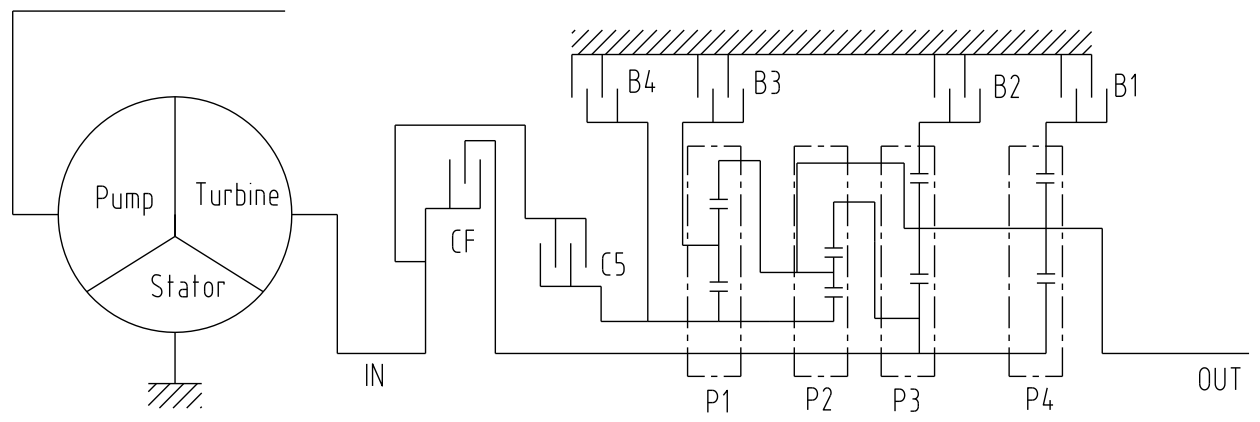

In the high-fidelity model, the gearbox considers the inertia of each component (represented by the rectangular block in Figure 3). As the number of teeth and inertia for each gear is known, the dynamic model of planetary gear train is easily obtained from the equations for a planetary gearset, shown in Eq. 10-13, where $\alpha, \beta, \gamma$ and $\theta$ is the angular displacement of sun gear, carrier, pinion and ring gear. $R_{S n}, R_{C n}, R_{P n}$ and $R_{R n}$ represent the radius of sun gear, carrier, pinion and ring gear respectively, while $\mathrm{n}$ means the number of planetary.

$$
\begin{aligned}
& \left\{\begin{array}{l}
\dot{\beta}_{1} R_{S 1}-\dot{\gamma}_{1} R_{P 1}=\dot{\alpha}_{1} R_{S 1} \\
\dot{\beta}_{1}\left(R_{S 1}+2 R_{P 1}\right)+\dot{\gamma}_{1} R_{P 1}=\dot{\theta}_{1} R_{R 1}
\end{array}\right. \\
& \left\{\begin{array}{l}
\dot{\theta}_{1} R_{S 2}-\dot{\gamma}_{2} R_{P 2}=\dot{\alpha}_{1} R_{S 2} \\
\dot{\theta}_{1}\left(R_{S 2}+2 R_{P 2}\right)+\dot{\gamma}_{2} R_{P 2}=\dot{\theta}_{2} R_{R 2}
\end{array}\right. \\
& \left\{\begin{array}{l}
\dot{\theta}_{1} R_{S 3}-\dot{\gamma}_{3} R_{P 3}=\dot{\theta}_{2} R_{S 3} \\
\dot{\theta}_{1}\left(R_{S 3}+2 R_{P 3}\right)+\dot{\gamma}_{3} R_{P 3}=\dot{\theta}_{3} R_{R 3}
\end{array}\right. \\
& \left\{\begin{array}{l}
\dot{\theta}_{1} R_{S 4}-\dot{\gamma}_{4} R_{P 4}=\dot{\theta}_{2} R_{S 4} \\
\dot{\theta}_{1}\left(R_{S 4}+2 R_{P 4}\right)+\dot{\gamma}_{4} R_{P 4}=\dot{\theta}_{4} R_{R 4}
\end{array}\right.
\end{aligned}
$$

To build the powertain system dynamic model with Lagrange method, the kinetic energy of gear box is presented by Eq. 14. The box consists with 10 components since some parts connect each other. Based on the mesh equations of gear, there are 10 variables and 8 constraint equations. The other 6 variables could be presented regard to input angular velocity $\dot{\theta}_{2}$ and output one $\dot{\theta}_{1}$. With visual work principle, the system visual work is shown by Eq. 15, where $A_{n}$ is the radius ration and explained in Nomenclature.

$$
\kappa=\kappa_{S 12}+\kappa_{C 1}+\kappa_{P 1}+\kappa_{R 1 C 234}+\kappa_{P 2}+\kappa_{S 34 R 2}+\kappa_{P 3}+\kappa_{R 3}+\kappa_{P 4}+\kappa_{R 4}
$$


An Optimal Gear Shifting Strategy for Heavy Mining Trucks with Trade-off Study between Trip Time and Fuel Economy

$$
\begin{aligned}
\delta W= & {\left[T_{S 12}\left(1+A_{1}\right)+T_{C 1}\left(1+A_{2}\right)+T_{R 1 C 234}+T_{R 3}\left(1+A_{3}\right)+T_{R 4}\left(1+A_{4}\right)\right] \delta \theta_{1}+} \\
& \left(-T_{S 12} A_{1}-T_{C 1} A_{2}+T_{S 34 R 2}-T_{R 3} A_{3}-T_{R 4} A_{4}\right) \delta \theta_{2}
\end{aligned}
$$

The Lagrange equations of system are shown in Eq.16-17,

$$
\begin{aligned}
\theta_{1}-\text { equation }: & \frac{d}{d t}\left(\frac{\partial \kappa}{\partial \dot{\theta}_{1}}\right) & =Q_{\theta_{1}} \\
\theta_{2}-\text { equation }: & \frac{d}{d t}\left(\frac{\partial \kappa}{\partial \dot{\theta}_{2}}\right) & =Q_{\theta_{2}}
\end{aligned}
$$

Taking the partial derivatives of the kinetic energy in Eq. 14 with respect to $\dot{\theta}_{2}$ and $\dot{\theta}_{1}$ and substituting them into Eq. 16 and 17 along with the generalized moments from Eq. (15) yield $\dot{\theta}_{2}$ and $\dot{\theta}_{1}$ equations of dynamics for the planetary gear set (Eq.18 and 19). The parameters of planetary gear set are shown in Table 2 .

$$
\begin{aligned}
& D_{11} \ddot{\theta}_{1}+D_{12} \ddot{\theta}_{2}=T_{S 12}\left(1+A_{1}\right)+T_{C 1}\left(1+A_{2}\right)+T_{R 1 C 234}+T_{R 3}\left(1+A_{3}\right)+T_{R 4}\left(1+A_{4}\right) \\
& D_{21} \ddot{\theta}_{1}+D_{22} \ddot{\theta}_{2}=-T_{S 12} A_{1}-T_{C 1} A_{2}+T_{S 34 R 2}-T_{R 3} A_{3}-T_{R 4} A_{4}
\end{aligned}
$$

Table 2 Planetary gear set parameters

\begin{tabular}{cccccc}
\hline $\begin{array}{c}\text { Planetary No. } \\
\text { No. }\end{array}$ & Parameter & $\begin{array}{c}\text { Radius } \\
(\mathbf{m m})\end{array}$ & $\begin{array}{c}\text { Inertia } \\
\left(\mathbf{k g} / \mathbf{m}^{2}\right)\end{array}$ & Gear teeth & Planet pinion No. \\
& Sun gear & 55.4 & $1.25 * 10^{-2}$ & 48 & \\
P1 & Ring gear & 92.35 & $2.41 * 10^{-1}$ & 80 & 6 \\
& Pinion & 18.45 & $4.81 * 10^{-5}$ & 16 & \\
& Sun gear & 35.8 & - & 31 & 4 \\
P2 & Ring gear & 96.7 & $1.7 * 10^{-1}$ & 81 & \\
& Pinion & 27.7 & $2.99 * 10^{-4}$ & 24 & 4 \\
& Sun gear & 53.3 & - & 42 & \\
& Ring gear & 116.85 & $1.73 * 10^{-1}$ & 95 & \\
& Pinion & 31.75 & $4.21 * 10^{-4}$ & 25 & \\
& Sun gear & 27.9 & - & 22 & \\
& Ring gear & 116.85 & $1.73 * 10^{-1}$ & 92 & \\
& Pinion & 44.85 & $2.82 * 10^{-3}$ & 35 & \\
\hline
\end{tabular}


An Optimal Gear Shifting Strategy for Heavy Mining Trucks with Trade-off Study between Trip Time and Fuel Economy

\subsection{Low-order Powertrain Model}

The low-order model is used to determine the optimal control law, because it solves quickly. The low-order model is a steady-state backwards model that the only input is the throttle angle (Chan et al., 2007), and thus, inertial effects are ignored and the system is assumed to be able to reach any desired behaviour instantly.

\subsubsection{Engine}

The engine fuel consumption model is based on empirically collected data. The data is stored in a map, which uses torque and speed to interpolate the fuel consumption rate. As shown in Eq. 20, the engine speed is a function of the vehicle speed $\omega_{W}$ and gearbox ratio. The mass of fuel is calculated by using the following interpolation function $f_{e}$ (Eq. 21 ), which is related with torque of engine $\tau_{I C E}$ and angular speed of engine $\omega_{I C E}$. Combining the measurement data of engine, the rate of fuel consumption $\dot{m}_{I C E, f}$ can be plotted in Figure 4.

$$
\begin{aligned}
& \omega_{I C E}=\omega_{W} \cdot i_{0} \cdot i_{R} \\
& \dot{m}_{I C E, f}=f_{e}\left(\tau_{I C E}, \omega_{I C E}\right)
\end{aligned}
$$

Figure 4 Fuel mass flow rate of a diesel engine based on experimental data

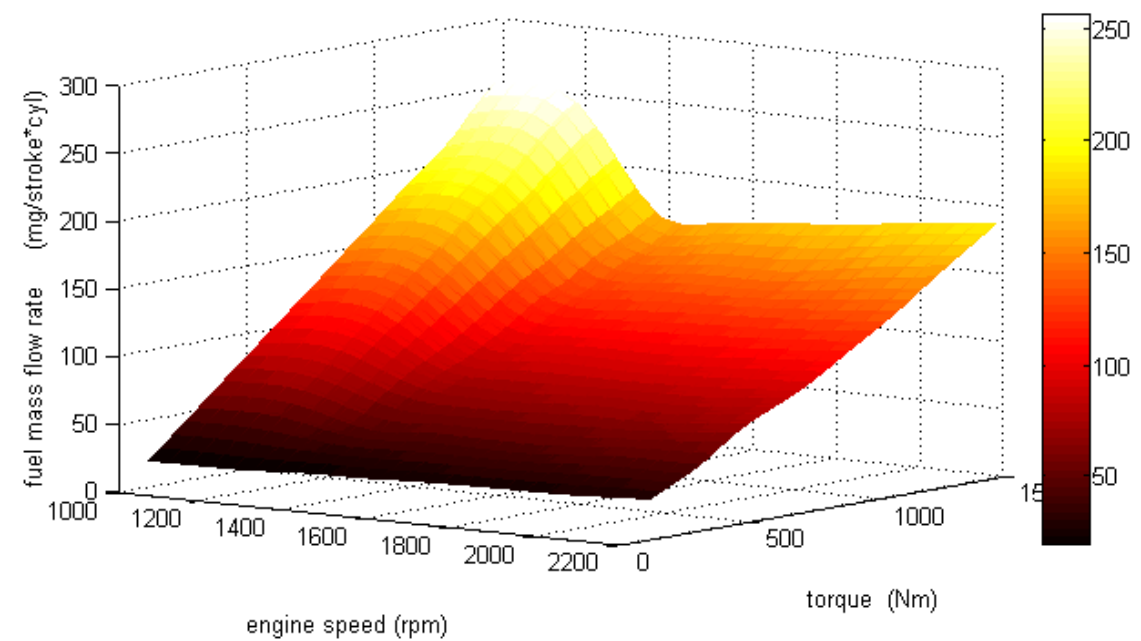

\subsubsection{Gearbox}

The gearbox is modelled as a simple gear ratio with no losses. The equations for the gearbox are given by: 
An Optimal Gear Shifting Strategy for Heavy Mining Trucks with Trade-off Study between Trip Time and Fuel Economy

$$
\begin{gathered}
\tau_{B}=\tau_{A} \cdot i_{R} \\
\omega_{A}=\omega_{B} \cdot i_{R}
\end{gathered}
$$

where, $\mathrm{A}$ is the input and $\mathrm{B}$ is the output of the gearbox, $\tau$ represents the torque, $\omega$ is angular velocity and $i_{R}(\mathrm{R}=1,2, \ldots, 5)$ is the gear ratio as shown in Table 1.

\section{Optimal Gear Shifting Strategy}

\subsection{Trip Information}

Optimization was used to determine the optimal gear shifting control law for the mining truck. Dynamic programming is an effective method for finding the optimal gear shifting strategies for a trip will that is fully defined beforehand. The control inputs of the mining truck can be formulated as an optimization problem, which can be solved by dynamic programming.

The vehicle trip data was gathered using Google Earth (Google Earth, 2014). It is approximately $3.4 \mathrm{~km}$ on a colliery in North-western China. As shown in Figure 5, the route starts at the star at the top, and ends at star at the bottom. The altitude and slope of the route was extracted at discrete intervals, then smoothed using high-order interpolation, as shown in Fig 5(b).

Figure 5 Trail road topography and estimated road slope

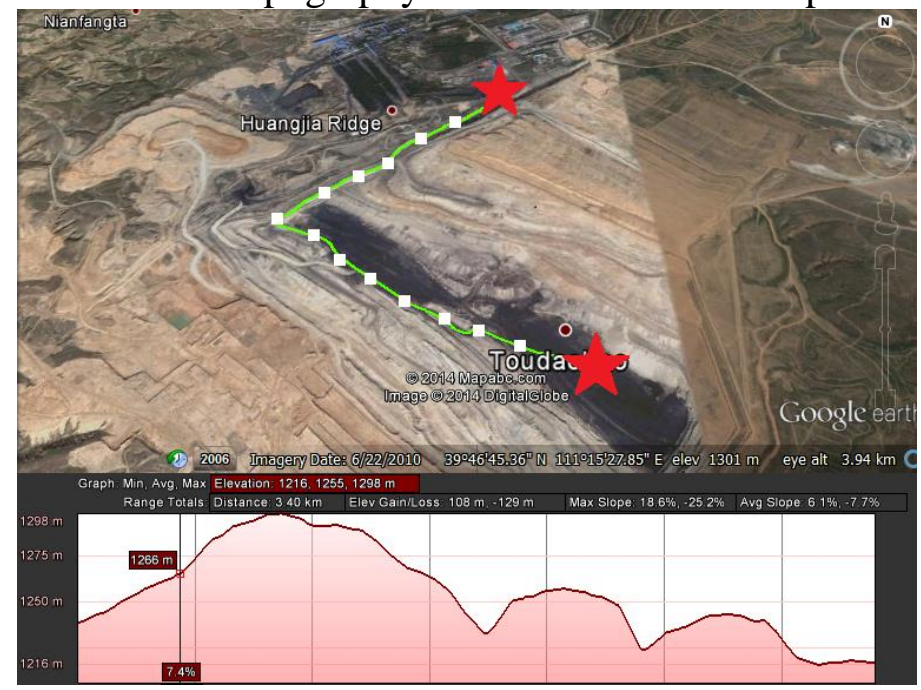

(a) 
An Optimal Gear Shifting Strategy for Heavy Mining Trucks with Trade-off Study between Trip Time and Fuel Economy

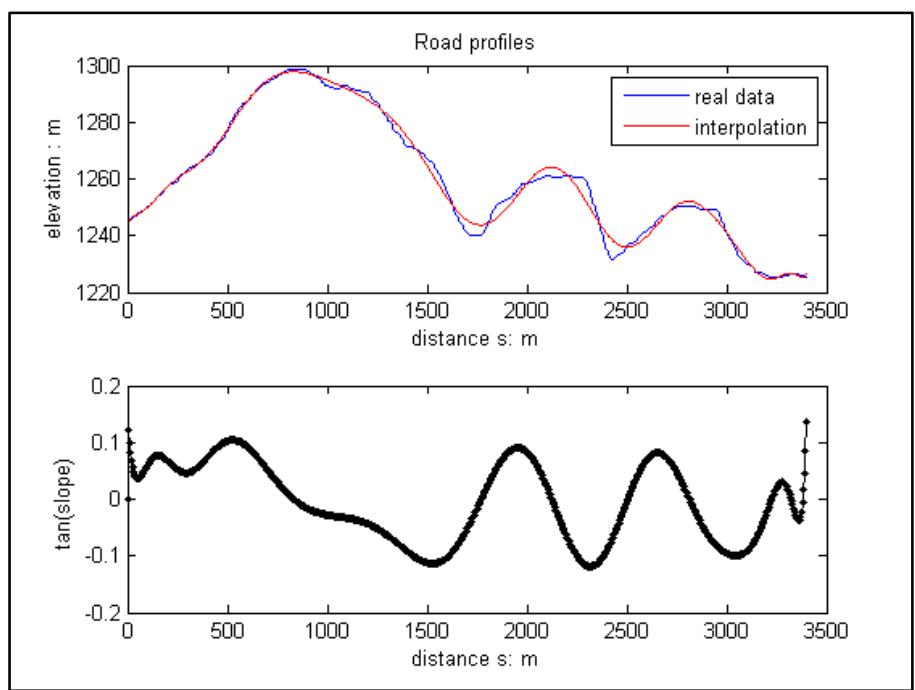

(b)

\subsection{Objective Function}

The problem is formulated in a way that minimizing fuel consumption and/or trip time can be achieved by changing two weighting parameters: $\lambda_{1}$ for fuel use and $\lambda_{2}$ for trip time. These parameters weigh the objective score to minimize trip time, fuel consumption, or both. The cost function at each instant $\mathrm{k}$ is:

$$
\xi_{k}=\lambda_{1} \cdot m_{f, k}+\lambda_{2} \cdot t_{k} \quad k=0,1,2, \ldots, N-1
$$

where the $\mathrm{N}$ is the number of steps of this optimal problem.

\subsection{Control Inputs and Constraints}

As the engine is mechanically connected to the wheels in the low-fidelity model (Eq. 20), its speed is a function of the vehicle speed and the gear ratio. The engine has a minimum idle speed of $750(\mathrm{rpm})$ and maximum speed of 2350(rpm); therefore each gear ratio in the transmission has a corresponding minimum and maximum speed, which are shown in Table 3.

The gear change input is a function of the current gear. Gear changes are only done in increments of $+1,0$, or -1 . If the current gear is the highest gear there are two admissible signals: 0 or -1 . Conversely if the current gear is the lowest gear there are two admissible signals: 0 or +1 . 
An Optimal Gear Shifting Strategy for Heavy Mining Trucks with Trade-off Study between Trip Time and Fuel Economy

Table3 The vehicle speed at different gear ratios

\begin{tabular}{ccc}
\hline Gear & $\begin{array}{c}\text { Minimum speed } \\
{[\mathbf{K m} / \mathbf{h}]}\end{array}$ & $\begin{array}{c}\text { Maximum speed } \\
{[\mathbf{K m} / \mathbf{h}]}\end{array}$ \\
$\mathbf{1}$ & 3.2 & 10.03 \\
$\mathbf{2}$ & 5.2 & 16.31 \\
$\mathbf{3}$ & 8.21 & 25.72 \\
$\mathbf{4}$ & 11.99 & 37.6 \\
$\mathbf{5}$ & 16.59 & 51.9 \\
\hline
\end{tabular}

An optimal control problem consists of an objective function, discrete state expressions with constraints, and control signals. The low-order powertrain optimal control problem is implemented in Matlab and can be found in Eq. 25 and 26. It represents the relationship between the current states at instant $\mathrm{k}$ and the states in last instant k-1.

$$
\text { Min } \quad J=\xi_{N}+\sum_{k=0}^{N-1} \xi_{k}
$$

Subject to constraints :

$$
\left\{\begin{array}{l}
v_{k}=v_{k-1}+\frac{h_{k-1}}{v_{k-1}} \cdot \ddot{\alpha}_{w, k-1}\left(g_{k-1}, \text { slope }_{k-1}\right) \\
m_{f, k}=m_{f, k-1}+\frac{h_{k-1}}{v_{k-1}} \cdot \dot{m}_{f, k-1}\left(g_{k-1}, \text { slope }_{k-1}\right) \\
g_{k}=g_{k-1}+u_{g, k-1}\left(g_{k-1}\right)
\end{array}\right.
$$

\subsection{Dynamic Programming Algorithm}

Dynamic programming tests all feasible control actions for each state in stage $k$ and chooses the control input which minimizes the cost function. For this type of optimal control problem, dynamic programming often starts at the end of the trip and proceeds backwards (Kirk, 2004). The specific dynamic programming for this deterministic multi-stage decision process will be expressed as the following steps and dynamic programming parameters are listed in Table 4. 
An Optimal Gear Shifting Strategy for Heavy Mining Trucks with Trade-off Study between Trip Time and Fuel Economy

Table4 Dynamic programming parameters

\begin{tabular}{cccc}
\hline Function & Parameter & Value & Unit \\
Number of steps & $N$ & 680 & \\
Step length & $h$ & 5 & $\mathrm{~m}$ \\
$\begin{array}{c}\text { Horizon } \\
\text { Velocity } \\
\text { discretization }\end{array}$ & $N \cdot h$ & 3400 & $\mathrm{~m}$ \\
Lower engine bound & $\omega_{e, \text { idl }}$ & 750 & $\mathrm{rpm} / \mathrm{h}$ \\
Upper engine bound & $\omega_{e, \max }$ & 2350 & $\mathrm{rpm}$ \\
Initial velocity & $v_{0}$ & 15 & $\mathrm{~km} / \mathrm{h}$ \\
Initial gear & $g_{0}$ & 2 & \\
\hline
\end{tabular}

The algorithm is briefly described below:

1. Set terminal cost to zero, $\xi_{N}\left(x_{N}\right)=0$

2. Let $k=N-1$

3. Solve the objective function to minimize cost, $J_{k}\left(x_{k}\right)=\min _{u_{g, k}}\left\{\xi_{k}\left(x_{k}, u_{g, k}\right)+J_{k+1}\left(f_{k}\left(x_{k}, u_{g, k}\right)\right)\right\} \quad$ where linear interpolation is used to calculate objective scores that fall between the discredited grids of states.

4. $\mathrm{N}=\mathrm{N}-1$. Go to step 2 .

5. When $\mathrm{N}=0$, the optimal control law can be found starting at $x_{0}^{*}$ and solving optimal control problem forwards.

\subsection{Comparison of Models with Dynamic Programming}

To verifying the dynamic programming algorithm used in low-order model, the optimized shifting result was used in high-fidelity model. The models are tested over a 3400-meter route which mentioned in 3.1. It starts from second gear and ends at fourth gear which is shown in Figure 6(a). 
An Optimal Gear Shifting Strategy for Heavy Mining Trucks with Trade-off Study between Trip Time and Fuel Economy

Figure 6 Comparison of results between the low-order model and high-fidelity model
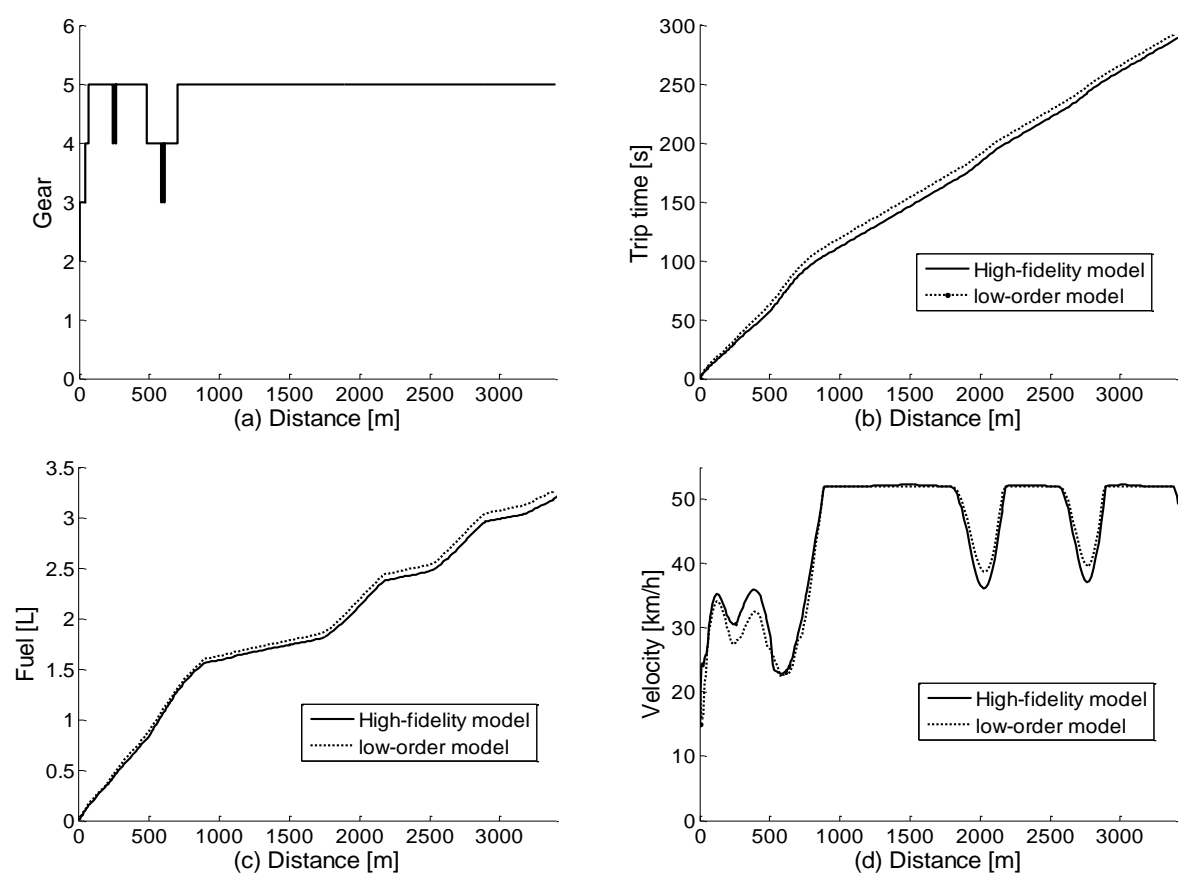

As shown in Figure 6(b)-(d), response of the high-fidelity and low-order model is compared, with both models having the same inputs. As can be seen from Figure 6(b) and (c), the results obtained from high-fidelity model, trip time and fuel consumption, are consistent with the solution of the low-order model. The control oriented model has a longer trip time around 294s than the high-fidelity model. The total fuel consumed over the trip is $3.21 \mathrm{~L}$ for the high-fidelity model and $3.27 \mathrm{~L}$ for the low-fidelity model, which is an error of $1.8 \%$.

In figure $6(\mathrm{~d})$, the vehicle speed of the high-fidelity model is slightly faster during $105 \mathrm{~m}$ to $200 \mathrm{~m}$, thus a shorter trip time and less fuel consumed is expected. In summary, the agreement between models is acceptable for the low-fidelity model to be used to find the optimal control law for the high-fidelity model.

\section{Results and Discussion}

\subsection{Tradeoff study and explanation}

The aim of optimizing gear shifting strategy is to minimize fuel consumption without significantly increasing trip time. The trade-off between trip time and fuel consumption was examined by using different 
An Optimal Gear Shifting Strategy for Heavy Mining Trucks with Trade-off Study between Trip Time and Fuel Economy

weights of $\lambda_{1}$ and $\lambda_{2}$ while solving the optimal control problem. The results can be found in Figure 7 .

Figure 7 demonstrates the trade-off between trip time and fuel use with varying weight coefficients. If only the trip time is weighted, the trip is the shortest and uses the most fuel. When only the fuel consumption is weighted, the trip is the longest, but does not have the lowest fuel consumption. When only fuel consumption is weighted (i.e. weights of $[1,0])$, one would expect the lowest fuel consumption. However, the lowest fuel consumption can be found with mixed weights of $[0.4,0.6]$. The minimum fuel consumption can be found when $\lambda_{1}$ and $\lambda_{2}$ are 0.4 and 0.6 respectively. For fuel consumption is related to trip time, the case with two weight include is a trade-off between trip time and fuel usage.

Figure $7 \quad$ Pareto curve of weight coefficients

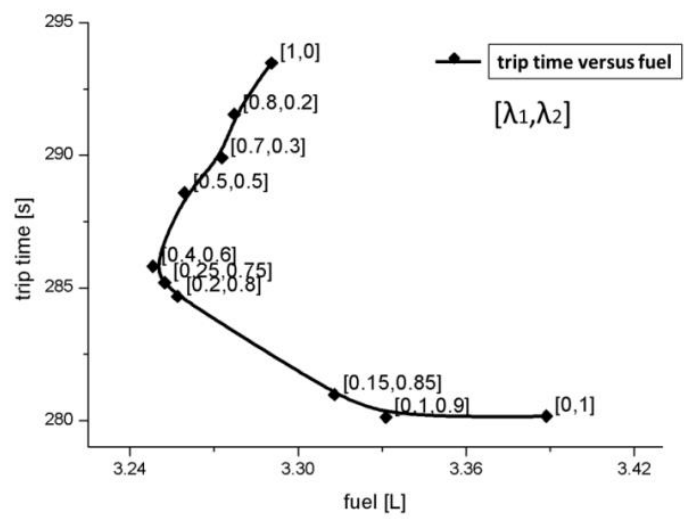

The shape of the curve in Figure 7 is unintuitive. Figure 8 is the ratio of fuel consumption to trip time versus $\lambda_{1}$. Although the minimum fuel consumption is obtained with a mixed weight, the minimum ratio appears in the case where only fuel consumption is considered. $\left(\lambda_{1}=1, \lambda_{2}=0\right)$

Figure 8 The ratio of fuel consumption and trip time 
An Optimal Gear Shifting Strategy for Heavy Mining Trucks with Trade-off Study between Trip Time and Fuel Economy

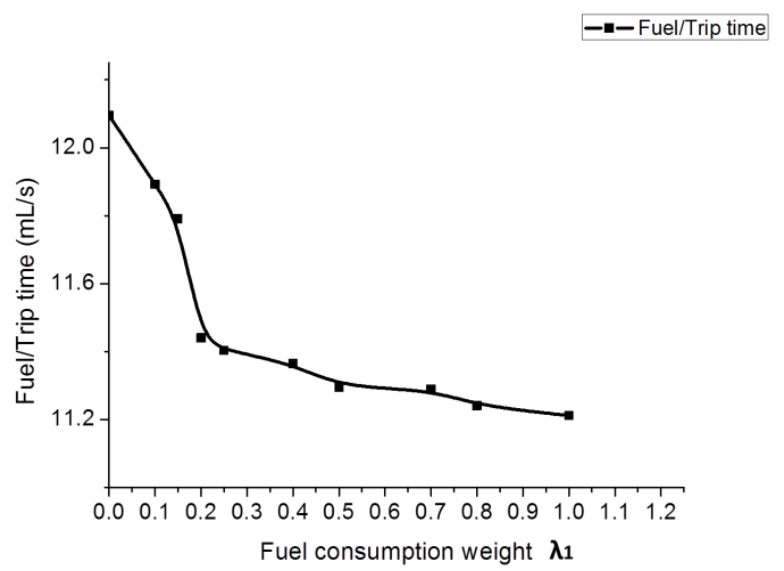

Setting weight parameters of objective function, three kind of gear shifting strategies are shown in Figure 9. The optimization of the gear shifting is presented for certain trip exhibited in Figure 6. By examining the engine operating points in Figure 10, it can be seen that a slower vehicle speed corresponding to longer trip time will cause the engine to operate outside of its most efficient region. As the engine speed is a function of vehicle speed, a mixed weighting will allow the engine to be controlled in its most efficient region.

Figure 9 The different shifting strategies for three cases

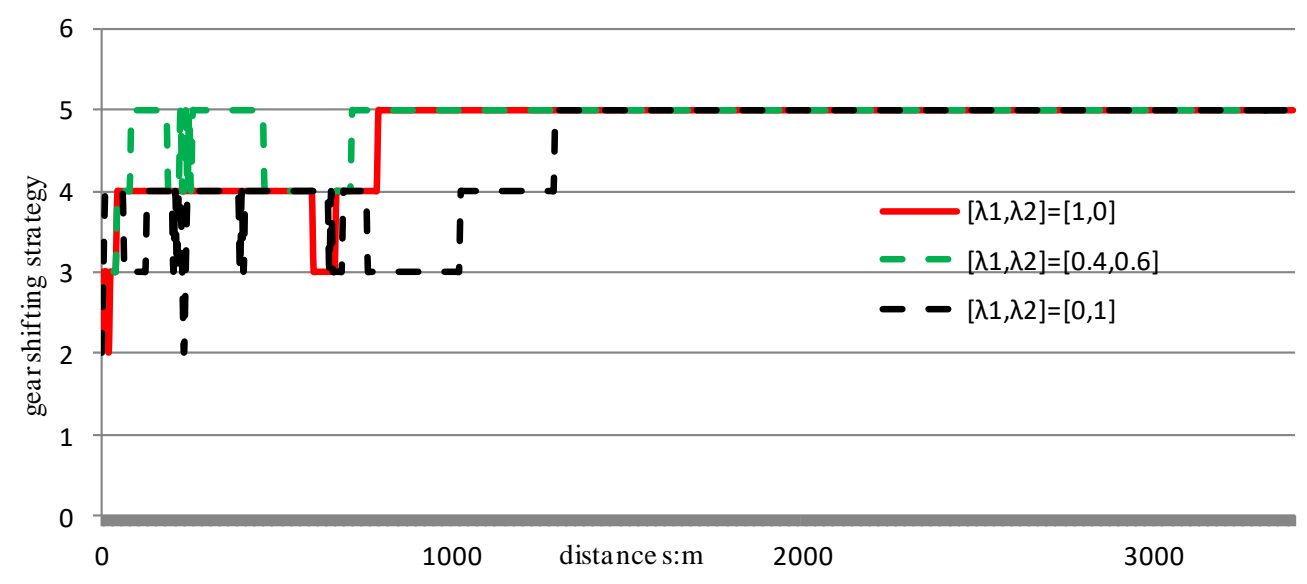

Figure 10 Engine operation points. a) weighted for speed, b) mixed weighting, c) weighted for fuel saving 
An Optimal Gear Shifting Strategy for Heavy Mining Trucks with Trade-off Study between Trip Time and Fuel Economy
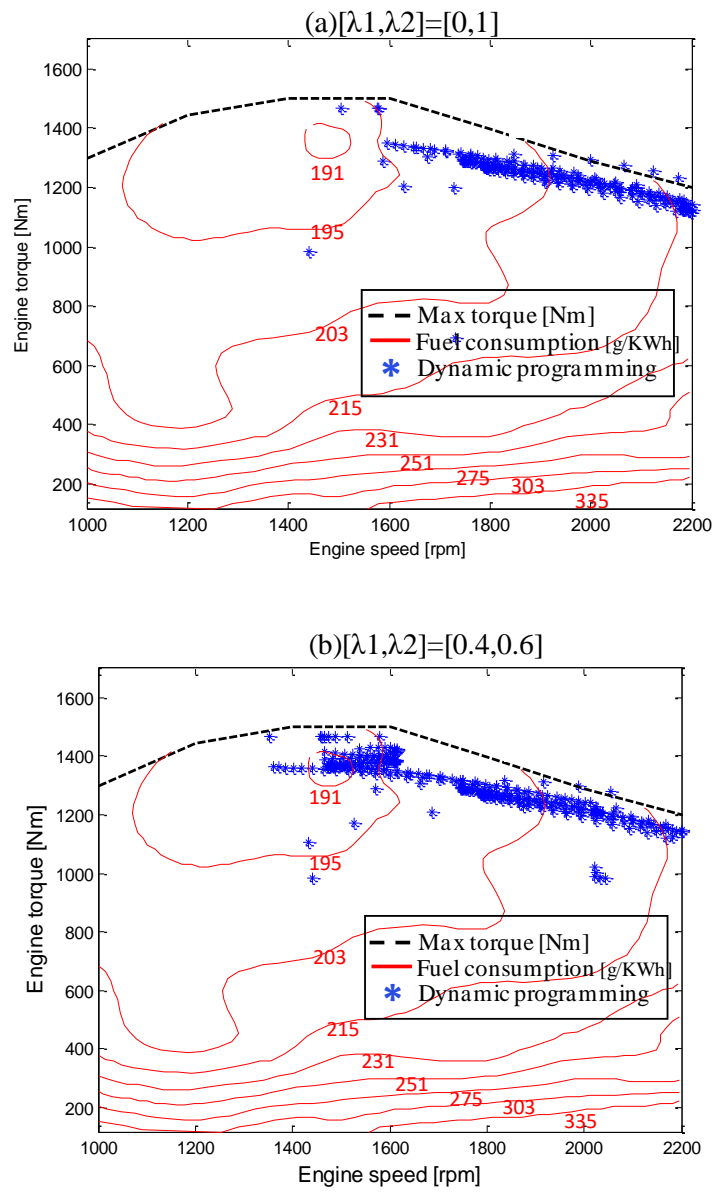

(c) $[\lambda 1, \lambda 2]=[1,0]$

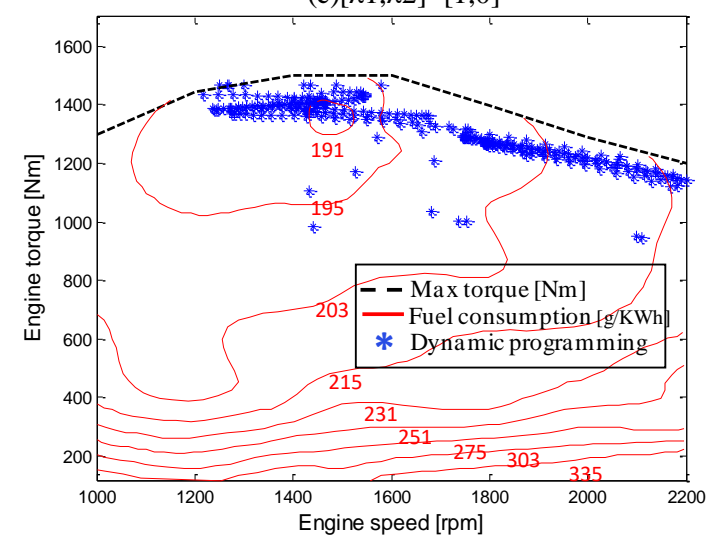


An Optimal Gear Shifting Strategy for Heavy Mining Trucks with Trade-off Study between Trip Time and Fuel Economy

\subsection{High-fidelity model simulation using optimal gear shifting strategy}

The optimal gear shifting strategy obtained by dynamic programming was used on the high-fidelity model of the mining truck, with fuel consumption and trip time weights of $\lambda_{1}=0.2$, and $\lambda_{2}=0.8$ respectively. The results from the high-fidelity model can be found below.

In this simulation, the results for trip time and fuel consumption with the current strategy are $291.3 \mathrm{~s}$ and $3.22 \mathrm{~L}$ respectively. The current strategy is rule-based and given from a transmission manufacturer. (Yu et al., 2006) When compared to the current control strategy, the optimized gear shifting strategy reduces trip time by more than $1.7 \%$ and fuel consumption around $1 \%$ simultaneously.

As shown in Figure 11, the main differences between the two strategies are at the beginning of the route. At 460 meters, the optimized strategy downshifts earlier than the current strategy, to produce more torque for uphill driving (see Fig.11). The optimal gear shifting strategy keeps it in third instead of fourth gear during 200 meter to 265 meters. In Figure 10 (c), the engine can be seen to be maintained in a high speed range where it operates more efficiently.

Figure 11 Simulation results by different gear shifting strategy
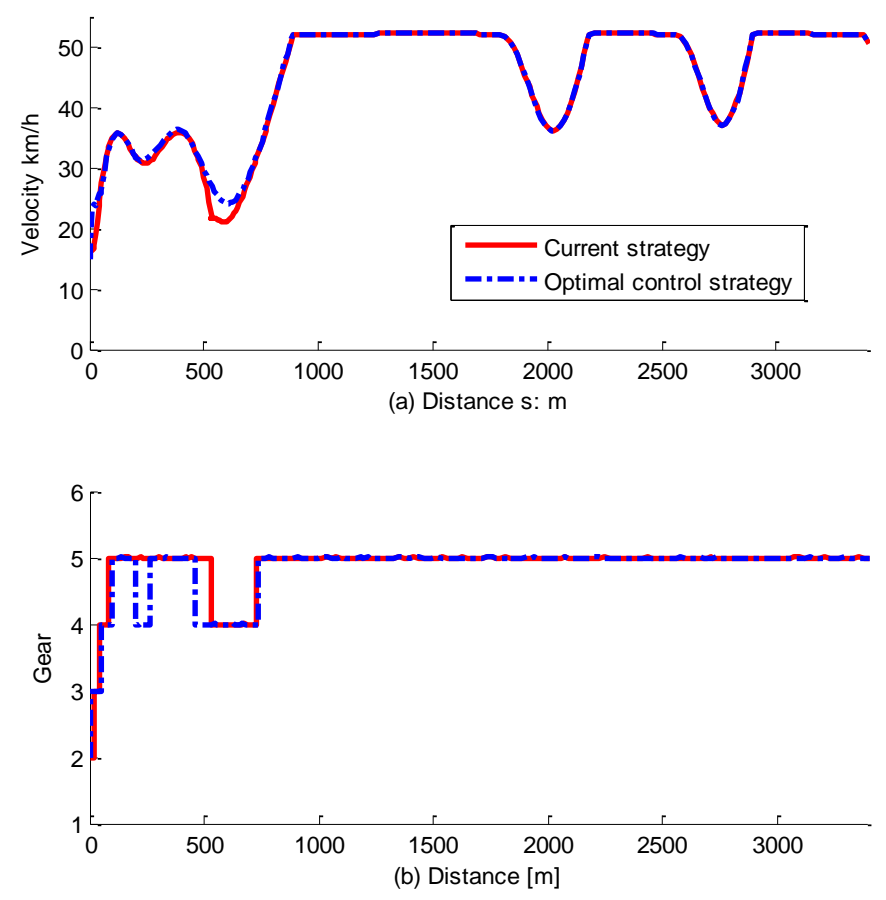


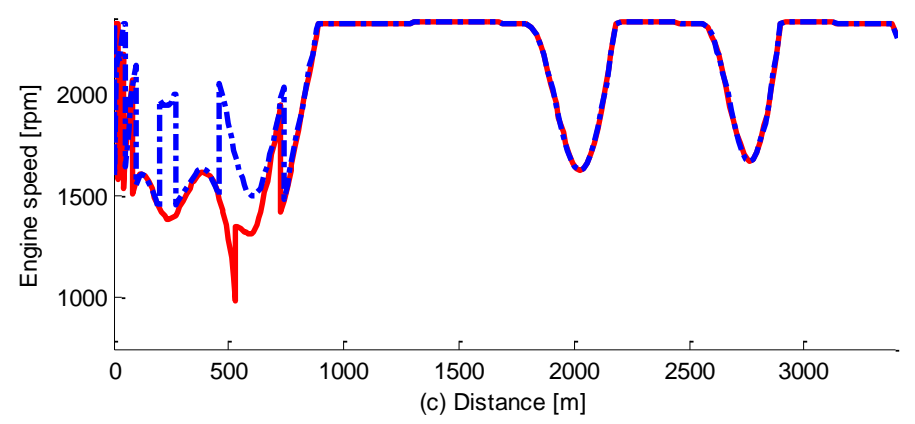

According to the reported production of the Hei Daigou Mine, 110 kilotons per day of raw coal was produced (Zhun neng News, 2011). Using a 30 ton truck, this would result in 3667 trips. Applying the optimized gear shifting strategy to the road topology in this mine, potentially forty-thousand litres of diesel can be saved per year.

\section{Conclusion}

This study shows the potential of an offline optimal controller on a heavy truck to save both fuel and time by using prior knowledge of the trip. A low-fidelity steady-state model and a high-fidelity quasi-static model of a turbocharged heavy mining truck was developed. A custom gear shifting strategy was applied to the two models and the results from the low order model were compared with the high-fidelity model, which were very consistent with each other. An objective function with weightings on the fuel consumption and trip time was developed, and dynamic programming was used to find the optimal control law which minimizes both. A Pareto curve was used to determine the optimal weightings for the controller, which reduced the fuel consumption and trip time by more than $1.7 \%$ and $1 \%$ respectively. Future work for the gear shifting controller is to validate the results from the high-fidelity model against experimental data from a real vehicle.

\section{Nomenclature}

$$
\begin{aligned}
& A_{1}=\frac{R_{R 2}}{R_{S 2}} \\
& A_{2}=\frac{R_{S 1} R_{R 2}}{R_{S 2}\left(R_{S 1}+R_{R 1}\right)}
\end{aligned}
$$


An Optimal Gear Shifting Strategy for Heavy Mining Trucks with Trade-off Study between Trip Time and Fuel Economy

$$
\begin{aligned}
& A_{3}=\frac{R_{S 3}}{R_{R 3}} \\
& A_{4}=\frac{R_{S 4}}{R_{R 4}} \\
& A_{5}=\frac{R_{R 1}}{R_{P 1}} \cdot A_{2} \\
& A_{6}=\frac{R_{R 2}}{R_{P 2}} \\
& A_{7}=\frac{R_{S 3}}{R_{P 3}} \\
& A_{8}=\frac{R_{S 4}}{R_{P 4}}
\end{aligned}
$$

$C_{p a} \quad$ Specific heat capacity of air at constant pressure, $C_{p a}=1011(\mathrm{~J} / \mathrm{kg} \cdot \mathrm{K})$

$k_{0} \quad$ Coefficient for calculating the pressure

$\dot{m}_{c}$ Mass flow rate of compressor $(\mathrm{kg} / \mathrm{s})$

$\dot{m}_{i m}$ Mass flow rate of air at the intake manifold $(\mathrm{kg} / \mathrm{s})$

$\dot{m}_{i e} \quad$ Mass flow rate of air from inlet manifold to engine $(\mathrm{kg} / \mathrm{s})$

$\dot{m}_{f}$ Mean mass flow rate fuel $(\mathrm{kg} / \mathrm{s})$

$m_{e x}$ Mass of fuel in exhaust manifold

$M_{c}$ Torque produced by the compressor $(\mathrm{N} \cdot \mathrm{m})$

$M_{f}$ Friction torque $(\mathrm{N} \cdot \mathrm{m})$

$M_{\text {ind }} \quad$ Engine indicated torque $(\mathrm{N} \cdot \mathrm{m})$

$M_{\text {load }} \quad$ Load torque $(\mathrm{N} \cdot \mathrm{m})$

$M_{t}$ Torque produced by the turbine $(\mathrm{N} \cdot \mathrm{m})$

$n_{r} \quad$ Number of revolutions per power cycle of an engine, $n_{r}=2$

$p_{a m b} \quad$ Ambient pressure, $p_{a m b}=101.35(\mathrm{kPa})$

$p_{c x}$ Pressure at the compressor outlet $(\mathrm{kPa})$

$p_{e x}$ Pressure in the exhaust manifold

$p_{\text {im }}$ Pressure at intake manifold inlet $(\mathrm{kPa})$

$Q_{l h v}$ Heating value of diesel, $Q_{l h v}=42.9 \cdot 10^{6} \quad(\mathrm{~J} / \mathrm{kg})$

$R$ Gas constant for air, $R=287(\mathrm{~J} / \mathrm{kg} \cdot \mathrm{K})$

$T_{a m b} \quad$ Ambient temperature, $T_{a m b}=298.15(\mathrm{~K})$

$T_{e x} \quad$ Temperature of the exhaust manifold

$T_{i m}$ Temperature at intake manifold (K)

$u_{f}$ Mass of fuel each cylinder and stroke (g/ (stroke·cylinder)) 
An Optimal Gear Shifting Strategy for Heavy Mining Trucks with Trade-off Study between Trip Time and Fuel Economy

$V_{i m}$ Volume of the inlet manifold $\left(\mathrm{m}^{3}\right)$

$\omega_{t c}$ Turbine angular velocity $(\mathrm{rad} / \mathrm{s}), \quad N_{e}=\frac{60}{2 \pi} \cdot \omega_{e}(\mathrm{rpm})$

$\eta_{c} \quad$ Efficiency of compressor

$\eta_{\text {ind }}$ Thermal efficiency

\section{References and Notes}

Chan C.C. (2007) 'The state of the art of electric, hybrid, and fuel cell vehicles', Proceedings of the IEEE,vol.95, no.4, pp.704-718.

Chang D.J. and Morlok E.K. (2005) 'Vehicle speed profiles to minimize work and fuel consumption', Journal of Transportation Engineering, vol.131, no.3, pp.173-182.

F. Xavier L.C. (2012) Optimal Speed Profiles for Passenger Cars with Gear Shifting. Master thesis, Linköping University, Linköping, Sweden.

Fröberg A., Hellström E. and Nielsen L. (2006) 'Explicit fuel optimal speed profiles for heavy trucks on a set of topographic road profiles' in SAE World Congress 2006: SAE Technical Papers, Detroit, United States, number 2006-01-1071.

$\mathrm{Fu}$ J. and Bortolin G. (2012) 'Gear shift optimization for off-road construction vehicles' in EWGT 2012: Proceedings of EWGT 2012 - 15th Meeting of the EURO Working Group on Transportation, Paris, France, pp.989-998.

Google Earth.[online] http://www.google.com/earth/( Accessed 28 April 2014).

Guzzella L. and Sciarretta A. (2007) Vehicle Propulsion Systems, $2^{\text {nd }}$ ed., Springer Berlin Heidelberg, New York.

Hellström E., Fröberg A. and Nielsen L. (2006) 'A real-time fuel-optimal cruise controller for heavy trucks using road topography information' in SAE World Congress 2006: SAE Technical Papers, Detroit, United States, number 2006-01-0008.

Hellström E., Ivarsson M., Åslund J. and Nielsen L. (2009) 'Look-ahead control for heavy trucks to minimize trip time and fuel consumption', Control Engineering Practice, vol.17, no.2, pp. 245-254.

Hellström E. (2010) Look-Ahead Control of Heavy Vehicles. PhD thesis, Linköping University, Linköping, Sweden.

Ivarsson M, Åslund J. and Nielsen L. (2009) 'Look-ahead controlconsequences of a non-linear fuel map on truck fuel consumption', 
An Optimal Gear Shifting Strategy for Heavy Mining Trucks with Trade-off Study between Trip Time and Fuel Economy

Proceedings of the Institution of Mechanical Engineers, Part D: Journal of Automobile Engineering, vol.223, no.10, pp.1223-1238.

Kim D., Huei P., Bai S. and Joel M.M. (2007) 'Control of integrated powertrain with electronic throttle and automatic transmission', IEEE Trans Control Systems Technol,no.15, pp.474-482.

Kirk D.E. (2004) Optimal Control Theory, Dover Publications, Mineola.

Liamas X., Eriksson L. and Sundström C. (2013) 'Fuel efficient speed profiles for finite time gear shift with multi-phase optimization' in 54th SIMS conference: Proceedings of the $54^{\text {th }}$ SIMS conference, Bergen, Norway.

Mensing F., Bideaux E., Trigui R. and Jeanneret B. (2013) 'Trajectory optimisation for eco-driving an experimentally verified optimisation method', Int. J. Vehicle Systems Modelling and Testing, vol. 8, no.4, pp.295-315.

Ngo V.D., Navarrete J.A.C, Hofman T, Steribuch $M$ and Serrarens A.(2013) 'Optimal gear shift strategies for fuel economy and driveability',Journal of Automobile engineering, vol.227, no.10, pp.1398-1413.

Nouveliere L., Braci M., Menhour L. and Luu H.T. (2008) 'Fuel consumption optimization for a city bus' in UKACC 2008: International Conference on Control 2008, UKACC, Manchester, England.

Saerens B., Vandersteen J., Persoons T., Swevers J., Diehl M. and Van den Bulck E. (2009) 'Minimization of the fuel consumption of a gasoline engine using dynamic optimization', Applied Energy, vol.86, no.9, pp.1582-1588.

Sauter I, Wuerthner M, Staudinger J, Kemler J, Wurthner M. Gearbox control device for controlling and regulating gearbox of e.g. truck, exhibits switching strategy to control and regulate gearbox with respect to e.g. vehicle mass, calculated by topography data of current position of motor vehicle, Patent ID: DE102009002387-A1, 2009-04-1.

Yanakiev D. and Kanellakopoulos I. (1995) Engine and transmission modeling for heavy-duty vehicle, UCLA Electrical Engineering, Path technical note 95-6.

Yu R.H., Sun D.Y. and Qin D.T. (2006) 'Study on dynamic gear-shift law of automated mechanical transmission', Transactions of the Chinese Society for Agricultural Machinery, vol.37, no.4, pp.1-4.

Zhun neng News. [online] http://www.nmg.xinhuanet.com /zt/2011-01/04/content_21780303.htm (Accessed 4 January 2011). 